\title{
A Budget Impact Model of Hemophilia Bypassing Agent Prophylaxis Relative to Recombinant Factor VIla On-Demand
}

\author{
Darshan A. Mehta, MS; Abiola O. Oladapo, BPharm, PhD; Joshua D. Epstein, PhD; \\ Aaron R. Novack, PhD; Ellis J. Neufeld, MD, PhD; and Joel W. Hay, PhD
}

\begin{abstract}
BACKGROUND: Hemophilia patients use factor-clotting concentrates (factor VIII for hemophilia A and factor IX for hemophilia B) for improved blood clotting. These products are used to prevent or stop bleeding episodes. However, some hemophilia patients develop inhibitors (i.e., the patient's immune system develops antibodies against these factor concentrates). Hence, these patients do not respond well to the factor concentrates. A majority of hemophilia patients with inhibitors are managed on-demand with the following bypassing agents: recombinant factor VIla (rFVIIa) and activated prothrombin complex concentrate (aPCC). The recently published U.S. registries Dosing Observational Study in Hemophilia (DOSE) and Hemostasis and Thrombosis Research Society (HTRS) reported higher rFVIla on-demand use for bleed management than previously described.
\end{abstract}

OBJECTIVE: To estimate aPCC and rFVIla prophylaxis costs relative to rFVIla on-demand treatment cost based on rFVIla doses reported in U.S. registries.

METHODS: A literature-based cost model was developed assuming a base case on-demand annual bleed rate (ABR) of 28.7 per inhibitor patient, which was taken from a randomized phase 3 clinical trial. The doses for rFVIla on-demand were taken from the median dose per bleed reported by the DOSE and HTRS registries. Model inputs for aPCC and rFVIIa prophylaxis (i.e., dosing and efficacy) were derived from respective randomized clinical trials. Cost analysis was from the U.S. payer perspective, and only direct drug costs were considered. The drug cost was based on the Medicare Part B 2014 average sale price (ASP). Two-way sensitivity and threshold analyses were performed by simultaneously varying on-demand $A B R$, prophylaxis efficacy, and unit drug cost. In addition to studying relative costs associated with on-demand and prophylaxis treatments, relative cost per bleeding episode avoided were also calculated for aPCC and rFVIla prophylaxis treatments. The prophylaxis efficacy reported in the trials were used to determine the number of bleeding episodes avoided.

RESULTS: Based on the median on-demand dose of $695 \mathrm{mcg}$ per $\mathrm{kg}$ per bleed, reported by the DOSE registry, the annual rFVIla on-demand cost was $\$ 34,009$ per $\mathrm{kg}$ of body weight. The annual rFVIla on-demand cost was $\$ 22,020$ per $\mathrm{kg}$ of body weight when the median dose of $450 \mathrm{mcg}$ per $\mathrm{kg}$ per bleed reported by the HTRS registry was considered. The annual cost rose to $\$ 38,461$ per $\mathrm{kg}$ of body weight when the rFVIla on-demand dose of $786 \mathrm{mcg}$ per kg per bleed among patients infusing an initial dose $\geq 250$ mcg per $\mathrm{kg}$ was considered. The aPCC (85 units per kg per every other day) and rFVIla ( 90 mcg per kg per every day) annual prophylaxis costs were $\$ 26,536$ and $\$ 60,700$, respectively. Also, aPCC and rFVIla prophylaxis treatments were estimated to prevent a total of 20.8 and 12.9 annual bleeding episodes, respectively. When compared with the on-demand dose of $695 \mathrm{mcg}$ per kg per bleed (DOSE registry), the annual aPCC and rFVIIa prophylaxis costs were $21.9 \%$ lower and $78.4 \%$ higher, respectively.
Additionally, aPCC prophylaxis saved $\$ 360$ per kg for each bleeding episode avoided. rFVIla prophylaxis cost \$2,066 per $\mathrm{kg}$ for each bleeding episode avoided. Compared with the on-demand dose of $450 \mathrm{mcg}$ per $\mathrm{kg}$ per bleed (HTRS registry), aPCC and rFVIla prophylaxis costs were $20.5 \%$ and $174.9 \%$ higher, respectively. In this case, aPCC and rFVIla prophylaxis treatment costs were \$217 per $\mathrm{kg}$ and \$2,995 per kg, respectively, for each bleeding episode avoided. aPCC and rFVIla prophylaxis costs were $31.0 \%$ lower and $57.8 \%$ higher, respectively, when compared with the rFVIla on-demand dose of 786 mcg per kg per bleed, among patients infusing an initial dose $\geq 250$ mcg per kg (HTRS registry). In this case, aPCC prophylaxis saved $\$ 573$ per $\mathrm{kg}$ for each bleeding episode avoided, while rFVIla prophylaxis costs $\$ 1,724$ per $\mathrm{kg}$ for each bleeding episode avoided. Results of the 2-way sensitivity analyses were robust in the majority of the scenarios considered.

CONCLUSIONS: aPCC prophylaxis may be cost saving for managing hemophilia patients with inhibitors who bleed frequently and infuse significant quantities of rFVIla on-demand.

J Manag Care Spec Pharm. 2016;22(2):149-57

Copyright $\odot 2016$, Academy of Managed Care Pharmacy. All rights reserved.

\section{What is already known about this subject}

Development of inhibitors remains one of the serious complications in the management of patients with hemophilia. The incidence of inhibitor development ranges from 5\% to 30\%, depending on type of hemophilia and severity.

Hemophilia patients with inhibitors can be managed on-demand or prophylactically with the use of bypassing agents. However, despite the benefits of prophylaxis, the majority are mostly managed on-demand.

Real-world data from U.S. registries showed significantly higher rFVIIa on-demand dosing compared with what has been studied in clinical trials and prescribed by physicians.

\section{What this study adds}

The cost of bypassing agent prophylaxis was estimated relative to the cost of rFVIIa on-demand, using real-world rFVIIa doses reported in 2 U.S. registries.

The study results indicated that aPCC prophylaxis may be cost saving in managing hemophilia patients with inhibitors who bleed frequently and infuse significant quantities of rFVIIa on-demand. 
$\mathrm{H}$ emophilia A and B are rare (prevalence of 1 in 10,000 males), congenital, and X-linked recessive disorders caused by the deficiency or absence of functional blood clotting factor VIII (FVIII) and factor IX (FIX), respectively. However, following exposure to factor-clotting concentrates, some hemophilia patients develop inhibitors (i.e., the patient's immune system develops an alloantibody against exogenously administered factor concentrates). The development of inhibitory antibodies to clotting FVIII or FIX remains one of the most serious complications in the management of patients with hemophilia. The incidence of inhibitor development in mild (FVIII concentration: $5 \%-40 \%$ of normal) or moderate (FVIII: $1 \%-5 \%$ of normal) and severe (FVIII: $<1 \%$ of normal) hemophilia A patients ranges from 5\%-10\% and 20\%-30\%, respectively. ${ }^{1}$ Approximately $2 \%-3 \%$ of patients with severe hemophilia B develop inhibitors. ${ }^{2}$ The development of inhibitors makes hemostasis difficult to achieve with the administration of FVIII or FIX products, necessitating the use of other treatment approaches.

Treatment of acute bleeding episodes in patients with hemophilia and inhibitors often involves the use of bypassing hemostatic agents, such as activated prothrombin complex concentrates (aPCC; FEIBA, Baxalta) or recombinant factor VII activated (rFVIIa; NovoSeven, Novo Nordisk A/S). Inhibitor patients may be treated with bypassing agents either on-demand or prophylactically. On-demand treatment is administered on an as needed basis, whereas prophylactic treatment is an infusion of bypassing agent on a regular schedule to prevent bleeds from occurring. In addition to approval for on-demand treatment, aPCC has regulatory approval for prophylaxis in the United States., ${ }^{3,4}$ The indication was obtained based on a randomized clinical trial comparing the 2 strategies. ${ }^{5}$ The recommended on-demand dosage for aPCC varies between 50 and 100 Units per kilogram (U per kg) given every 6-12 hours (not exceeding $200 \mathrm{U}$ per kg per day) until hemostasis is achieved. The prophylaxis dosage for aPCC is $85 \mathrm{U}$ per $\mathrm{kg}$ given every other day. ${ }^{4}$ The recommended ondemand dosage for rFVIIa is 90 micrograms per $\mathrm{kg}$ (mcg per $\mathrm{kg}$ ) administered every 2-3 hours until hemostasis is achieved. ${ }^{6}$ The European label for rFVIIa also includes a dosing strategy of a single infusion of $270 \mathrm{mcg}$ per $\mathrm{kg}$ of rFVIIa for on-demand treatment of bleeding episodes but does not provide guidance on follow-up infusions, if any are required. ${ }^{7}$

Randomized clinical trials have documented the efficacy and clinical benefits associated with secondary prophylaxis with bypassing agents. In the aPCC prophylaxis study, aPCC prophylaxis reduced all bleeding episodes by $72.5 \%(P=0.0003)$ compared with patients treated on-demand.,5 Similar prophylaxis benefit was reported in the Pro-FEIBA study, where a $62 \%$ reduction in bleeding episodes $(P<0.001)$ was achieved with aPCC prophylaxis, compared with on-demand, given at a dose of $85 \mathrm{U}$ per kg thrice weekly on nonconsecutive days. ${ }^{8}$ rFVIIa prophylaxis administered at a dose of $90 \mathrm{mcg}$ per $\mathrm{kg}$ per day or $270 \mathrm{mcg}$ per $\mathrm{kg}$ per day achieved a $45 \%$ and $59 \%$ reduction $(P<0.0001)$, respectively, in bleeding episodes during the prophylaxis period. ${ }^{9}$ In addition to the primary effect of reduction in the frequency of bleeding episodes, bypassing agent prophylaxis reportedly reduced bleeding in joints and target joints, reduced the development of new target joints, reduced pain, and improved health-related quality of life and productivity in patients. ${ }^{5,10-12}$

However, unlike standard of care for noninhibitor hemophilia patients, ${ }^{13}$ the majority of hemophilia patients with inhibitors are still managed on-demand. ${ }^{5,8,9}$ The high per-unit cost of bypassing agents has been reported as a significant cost driver in the management of hemophilia patients with inhibitors. This perceived high cost of prophylaxis therapy may be a barrier to bypassing agent prophylaxis..$^{14,15}$ The cost of aPCC prophylaxis is estimated to be 2.4 times higher than that of on-demand therapy. ${ }^{8,16}$

Over the past decade, treatment of bleeding episodes has increasingly shifted from hemophilia treatment centers (HTCs) and hospitals to home-based settings. ${ }^{17}$ Recently published real-world data from U.S. registries showed higher rFVIIa on-demand dosing compared with what has been studied in clinical trials. ${ }^{5,6}$ The real-world dosing is even higher than recommended by physicians. ${ }^{17-19}$ The median (range) total dose of rFVIIa reported in the Haemophilia and Thrombosis Research Society (HTRS) registry and the Dosing Observational Study in Haemophilia (DOSE) registry was $450 \mathrm{mcg}$ per kg per bleeding episode (46-43,200 mcg per kg per bleeding episode) and 695 mcg per kg per bleeding episode (74-21,257 mcg per kg per bleeding episode), respectively. ${ }^{17,18}$ In addition, the HTRS registry reported a median dose of $786 \mathrm{mcg}$ per kg per bleeding episode (250-18,774 mcg per kg per bleeding episode) among patients whose initial dose was greater than $250 \mathrm{mcg}$ per $\mathrm{kg}$ (megadoses). ${ }^{19}$ The clinical characteristics of this subgroup of patients who have initial megadoses are similar to the total population in the HTRS registry in terms of bleed location and bleed type. However, the patient subgroups with high doses are usually treated at home and tend to be pediatric patients and patients with limited venous access. ${ }^{17-19}$

Given the high on-demand dosing of rFVIIa in real-world settings, the incremental cost of prophylaxis in the United States may be less than previously thought. Since the maximum recommended daily dose for aPCC is $200 \mathrm{U}$ per $\mathrm{kg}$, it is unlikely that the cost of aPCC on-demand will be greater than aPCC prophylaxis. In the absence of published registry data for aPCC on-demand, the primary objective of this study was to estimate the cost of bypassing agent prophylaxis relative to the cost of rFVIIa on-demand using actual rFVIIa doses reported in the DOSE and HTRS registries. Additionally, a similar 
analysis was conducted that made use of median on-demand aPCC dosage from the FEIBA NF PASS study (unpublished data, Baxalta, October 10, 2014); results are presented in the Discussion section.

\section{Methods}

A literature-based budget impact model was developed using Microsoft Excel (Microsoft Corp., Redmond, WA). The relative clinical efficacy of prophylactic usage and median on-demand usage of bypassing agents were derived from relevant clinical trials and registry data, respectively. The annual cost of rFVIIa on-demand was calculated using the median dosage reported in each registry (DOSE and HTRS) and compared independently with the aPCC (85 U per kg per day [QD]) and rFVIIa prophylaxis (90 mcg per kg per every other day [QOD]). The resulting annual cost per $\mathrm{kg}$ for prophylaxis treatment was calculated and compared with the annual on-demand cost of treatment of bleeding episodes with rFVIIa. The primary study outcome of the model was the relative annual cost difference between prophylaxis and on-demand treatments. Also, costs per bleeding episode avoided were calculated. Further, by employing the relative annual cost difference, the budget impact considerations, in terms of per member per month (PMPM), for a hypothetical plan of 10 million members to adopt a prophylaxis regimen for treating hemophilia patients with inhibitor was calculated. The model was developed from a U.S. payer perspective with a 1-year time frame.

\section{Model Inputs and Model Parameter Assumptions}

The HTRS registry was initially set up in 1999 and relaunched in 2004 as a web-based registry that included 87 U.S. HTCs. It was populated based on retrospective entry of treatment logs from patient and caregiver reports to HTCs at periodic visits. From 2004 to 2008, the registry collected information on 2,041 bleeding rFVIIa-treated episodes. ${ }^{18,19}$ Unlike the HTRS registry, the DOSE registry was established to collect information on treatment of acute bleeds in home settings from 2008 to 2009 across 20 U.S. HTCs. The data in this registry were collected via diary entry by patients or caregivers responsible for home-based care. The patients or caregivers were required to complete the diary for at least 90 days. ${ }^{17}$ Our base case model assumed that bleeding episodes were treated with the median total on-demand dose reported for rFVIIa in the DOSE and HTRS registries. ${ }^{17-19}$

The median annualized bleed rate of 28.7 reported for patients treated on-demand in the aPCC prophylaxis study was assumed for the base case scenario. ${ }^{5}$ This rate was similar to the average 6-month bleed rate of 13.1 for patients treated on-demand obtained in the Pro-FEIBA study. ${ }^{8}$ Model inputs for dosing and efficacy of aPCC (85 U per kg per QOD) and rFVIIa prophylaxis (90 mcg per $\mathrm{kg}$ per QD) were based on the

\section{TABLE 1 Base Case Parameters}

\begin{tabular}{|c|c|c|}
\hline \multicolumn{3}{|c|}{ Prophylaxis } \\
\hline & rFVIIa Prophylaxis & aPCC Prophylaxis \\
\hline Dose & $90 \mathrm{mcg} / \mathrm{kg}^{9}$ & $85 \mathrm{U} / \mathrm{kg}^{5}$ \\
\hline Dosage frequency & Daily $^{9}$ & Every other day ${ }^{5}$ \\
\hline Per unit cost & $\$ 1.705^{23}$ & $\$ 1.64423$ \\
\hline \% ABR reduction & $45 \%{ }^{9}$ & $72.5 \%^{5}$ \\
\hline ABR on demand & $28.7^{5}$ & $28.7^{5}$ \\
\hline $\begin{array}{l}\text { Annual number of breakthrough } \\
\text { bleeds on prophylaxis }\end{array}$ & 15.8 & 7.9 \\
\hline $\begin{array}{l}\text { Median dosage per bleeding } \\
\text { episode while on prophylaxis }\end{array}$ & 220 & $1^{20}$ \\
\hline \multicolumn{3}{|c|}{ On-Demand } \\
\hline & $\begin{array}{l}\text { rFVIIa On-Demand } \\
\text { (DOSE Registry) }\end{array}$ & $\begin{array}{l}\text { rFVIIa On-Demand } \\
\text { (HTRS Registry) }\end{array}$ \\
\hline $\begin{array}{l}\text { Median dose per bleeding } \\
\text { episode }(\mathrm{mcg} / \mathrm{kg})\end{array}$ & $695^{17}$ & $\begin{array}{l}450^{19,20} \\
786^{\mathrm{a}, 19,20}\end{array}$ \\
\hline Per unit cost & $\$ 1.705^{23}$ & $\$ 1.705^{23}$ \\
\hline $\begin{array}{l}\text { Average body weight of } \\
\text { patient }(\mathrm{kg})\end{array}$ & 50 & 50 \\
\hline \multicolumn{3}{|c|}{$\begin{array}{l}\text { "Among patients whose initial dose was greater than } 250 \text { mcg per kg (megadoses). } \\
\text { ABR=annual bleed rate; aPCC = activated prothrombin complex concentrate; } \\
\text { DOSE = Dosing Observational Study in Hemophilia; HTRS=Hemostasis and } \\
\text { Thrombosis Research Society; } \mathrm{kg}=\text { kilogram; } \mathrm{m} c \mathrm{~h} / \mathrm{kg}=\text { microgram per kilogram; } \\
\text { rFVIIa = recombinant factor VIIa; U/kg = Unit per kilogram. }\end{array}$} \\
\hline
\end{tabular}

aPCC and rFVIIa trials. ${ }^{5,9}$ The median dose reported to stop a bleeding episode with aPCC and rFVIIa in the FENOC trial was assumed in the base case scenario for the treatment of breakthrough bleeds during prophylaxis: a median of 1 infusion for aPCC and 2 infusions for rFVIIa. ${ }^{20}$ Furthermore, the model assumed $100 \%$ compliance with the prophylaxis regimen, and the frequency of bleeding episodes was reduced by the percentage reported in the aPCC and rFVIIa trials (Table 1).

\section{Cost Inputs}

For hemophilia patients with inhibitors, the cost of bypassing agents accounts for a substantial proportion (45\%-93\%, depending on severity of disease and treatment regimen) of the total health care costs associated with treatment. ${ }^{21,22}$ Consequently, this study only considered direct drug costs associated with bypassing agents. Drug costs were based on the 2014 average sale price (ASP) from Medicare Part B. ${ }^{23}$ There is an increasing trend of payers shifting towards ASP-based reimbursement. ${ }^{24}$ The unit costs of aPCC and rFVIla used for base case analysis were $\$ 1.64$ per $\mathrm{U}$ and $\$ 1.71$ per mcg, respectively (Table 1). The total cost for on-demand and prophylactic usage of factors was calculated per $\mathrm{kg}$ of body weight. Actual costs of the products vary among clinical settings and payer and pharmacy configurations in ways not readily discernable from available data. But the Medicare ASP data can serve as a means of comparison. All costs were measured in 2014 U.S. dollars. 


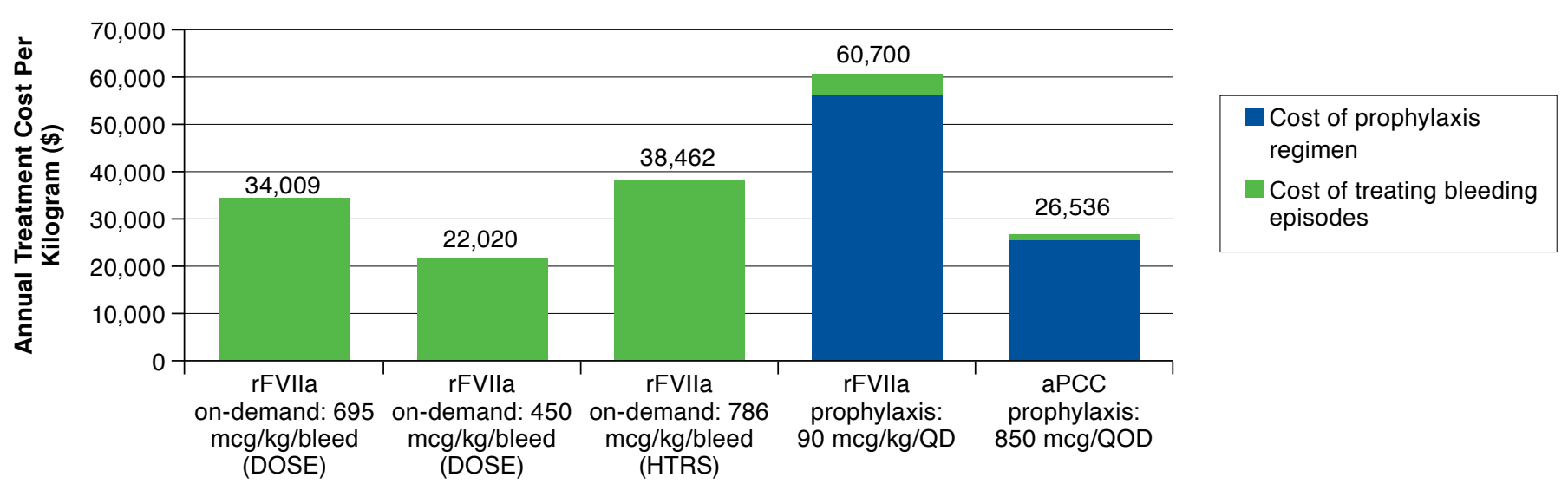

aPCC = activated prothrombin complex concentrate; DOSE = Dosing Observational Study in Hemophilia; HTRS = Hemostasis and Thrombosis Research Society; $\mathrm{kg}=$ kilogram; $\mathrm{mcg} / \mathrm{kg}=$ microgram per kilogram; QD = every day; QOD=every other day; $r F V I I a=$ recombinant factor VIIa.

\section{Sensitivity Analyses}

Two-way sensitivity and threshold analyses were performed to assess the robustness of outcomes, as well as to determine break-even values by varying the model input parameters used in the base case scenario. For both registries, 2-way sensitivity analyses were performed by simultaneously varying the ondemand annual bleed rate (ABR), percentage bleed reduction (i.e., efficacy) with prophylaxis, and unit cost of bypassing agents. The parameters were varied over a range of $25 \%$ in either direction. Also, the median on-demand doses reported in the registries were varied to determine the point of cost neutrality between the on-demand and prophylaxis regimens. Variation in model results because of heterogeneity of unit costs was assessed by simultaneously varying the unit costs of aPCC and rFVIIa over the range covering ASP and wholesale acquisition cost (WAC) prices. Additional sensitivity analyses were done using an aPCC prophylaxis dosing regimen of $85 \mathrm{U}$ per $\mathrm{kg}$ thrice weekly with a $62 \%$ efficacy and a rFVIIa prophylaxis dosing regimen of $270 \mathrm{mcg}$ per $\mathrm{kg}$ per day with a $59 \%$ efficacy. ${ }^{8,9}$

\section{Results}

\section{Comparison with rFVIla On-Demand Dose Per Bleeding Episode from the DOSE Registry}

In the base case scenario, the annual cost of rFVIIa on-demand was $\$ 34,009$ per $\mathrm{kg}$ when the median on-demand dose of 695 mcg per kg per bleeding episode was considered, as reported by the DOSE registry. The annual cost of aPCC prophylaxis was $\$ 26,535$ per $\mathrm{kg}$. This represents a $21.9 \%$ reduction in annual cost for the aPCC prophylaxis, with an annual cost savings of $\$ 7,474$ per $\mathrm{kg}$. In addition, aPCC prophylaxis was estimated to prevent a total of 20.8 bleeding episodes annually and save $\$ 360$ per kg for each bleeding episode avoided.
The annual cost of rFVIIa prophylaxis was $\$ 60,700$ per $\mathrm{kg}$. Compared with the rFVIIa on-demand cost $(\$ 34,009$ per $\mathrm{kg})$, the rFVIIa prophylaxis cost was $78.4 \%$ higher (Figure 1 ). rFVIIa prophylaxis was estimated to prevent a total of 12.9 bleeding episodes annually and thus cost $\$ 2,066$ per $\mathrm{kg}$ for each bleeding episode avoided (Appendix A, available in online article).

\section{Comparison with rFVIIla On-Demand Dose Per Bleeding Episode from the HTRS Registry}

The annual cost of rFVIIa on-demand was $\$ 22,020$ per $\mathrm{kg}$, when an overall on-demand median dose of $450 \mathrm{mcg}$ per $\mathrm{kg}$ per bleeding episode was considered, as per the HTRS registry. Thus, aPCC prophylaxis $(\$ 26,535$ per $\mathrm{kg}$ ) results in a $20.5 \%$ higher cost and an additional $\$ 217$ per $\mathrm{kg}$ for each bleeding episode avoided. On the other hand, the annual rFVIIa prophylaxis cost $(\$ 60,700$ per $\mathrm{kg})$ was $174.9 \%$ higher compared with the annual rFVIIa on-demand cost. This translates into an additional cost of $\$ 2,995$ per $\mathrm{kg}$ for each bleeding episode avoided (Appendices B and C, available in online article).

The annual cost of rFVIIa on-demand was $\$ 38,461$ per $\mathrm{kg}$, when a median on-demand dose of $786 \mathrm{mcg}$ per $\mathrm{kg}$ per bleeding episode was considered, reported among patients infusing an initial rFVIIa dose greater than $250 \mathrm{mcg}$ per $\mathrm{kg}$. Thus, aPCC prophylaxis $(\$ 26,535$ per $\mathrm{kg}$ ) results in a $31 \%$ lower cost with an annual cost savings of $\$ 11,926$ per $\mathrm{kg}$. Based on the aPCC prophylaxis efficacy, this strategy saves $\$ 573$ per $\mathrm{kg}$ for each bleeding episode avoided. On the other hand, rFVIIa prophylaxis $(\$ 60,700$ per $\mathrm{kg}$ ) results in a $57.8 \%$ higher cost and an additional $\$ 1,724$ per $\mathrm{kg}$ for each bleeding episode avoided (Appendices B and C). 
TABLE 2

\begin{tabular}{|c|c|c|c|c|}
\hline & $\begin{array}{c}\text { Base Case } \\
\text { Value }\end{array}$ & $\begin{array}{c}\text { DOSE } \\
\text { Registry } \\
695 \mathrm{mcg} / \mathrm{kg}\end{array}$ & \begin{tabular}{|c|} 
HTRS \\
Registry \\
$786 \mathrm{mcg} / \mathrm{kg}$
\end{tabular} & $\begin{array}{c}\text { HTRS } \\
\text { Registry } \\
450 \mathrm{mcg} / \mathrm{kg}\end{array}$ \\
\hline \multicolumn{5}{|c|}{ aPCC Prophylaxis (85 U/kg) } \\
\hline Prophylaxis efficacy & $72.50 \%$ & $\mathrm{NA}^{\mathrm{a}}$ & $N A^{a}$ & $185.09 \%$ \\
\hline ABR in patients & 28.7 & 22.2 & 19.5 & 35.0 \\
\hline Unit cost $(\$)$ & 1.64 & 2.11 & 2.38 & 1.36 \\
\hline \multicolumn{5}{|c|}{ rFVIIa Prophylaxis $(90 \mathrm{mcg} / \mathrm{kg}$ ) } \\
\hline Prophylaxis efficacy & $45 \%$ & $348.04 \%$ & $297.48 \%$ & $465.82 \%$ \\
\hline ABR in patients & 28.7 & 54.9 & 47.7 & 93.3 \\
\hline Unit cost $(\$)$ & 1.71 & $\mathrm{NA}^{\mathrm{b}}$ & $N A^{b}$ & $N A^{b}$ \\
\hline \multicolumn{5}{|c|}{  } \\
\hline
\end{tabular}

\section{Budget Impact Considerations}

Considering the prevalence of hemophilia inhibitor patients (5\%-10\% of unselected hemophilia patients) ${ }^{1,2}$ a health plan with 10 million enrollees the plan would have, on average, 50 patients with inhibitor formation. The estimated PMPM of adopting an aPCC prophylaxis regimen ranges from $-\$ 0.25$ to $\$ 0.09$, while the PMPM for rFVIIa prophylaxis ranges from $\$ 0.46$ to $\$ 0.81$, depending on median rFVIIa on-demand dose considered (Appendix D, available in online article).

\section{Sensitivity Analyses}

1-Way Threshold Analyses. Table 2 represents the results of threshold analysis on the ABR, prophylaxis efficacy, and unit cost with aPCC and rFVIIa prophylaxis treatments when compared with the DOSE and HTRS on-demand dosing. Looking at Table 2, we can infer that when the median on-demand dose of rFVIIa from DOSE (695 mcg per kg per bleeding episode) was considered, aPCC prophylaxis was cost saving at $A B R \geq 22.2$, aPCC unit price $\leq \$ 2.11$ or efficacy lower than base case. However, when compared with the median on-demand dose of rFVIIa from HTRS (450 mcg per kg per bleeding episode), aPCC prophylaxis was cost saving at $\mathrm{ABR} \geq 35$, aPCC unit price $\leq \$ 1.36$ or efficacy greater than $100 \%$. When the median on-demand dose (786 mcg per kg per bleeding episode) was considered, among patients who infused an initial rFVIIa dose greater than 250 mcg per kg in the HTRS registry, aPCC prophylaxis was cost saving at $A B R \geq 19.5$, aPCC unit price $\leq \$ 2.38$ or efficacy lower than base case.

When comparing rFVIIa prophylaxis with an rFVIIa median on-demand dose of $450 \mathrm{mcg}$ per $\mathrm{kg}$ per bleeding episode (HTRS), $695 \mathrm{mcg}$ per kg per bleeding episode (DOSE), and 786 mcg per kg per bleeding episode (HTRS: patients with initial dose $>250 \mathrm{mcg}$ per kg), rFVIIa prophylaxis was only cost sav- ing at $A B R \geq 93.3,54.9$, and 47.7, respectively. rFVIIa prophylaxis was not cost saving at a positive unit price or efficacy of $100 \%$ in any of these scenarios.

2-Way Sensitivity and Threshold Analyses. The results of the 2-way sensitivity and threshold analyses present scenarios where aPCC or rFVIIa prophylaxis may be cost saving compared with rFVIIa on-demand treatment.

Comparison with rFVIIa on-demand dose (695 mcg per $\mathrm{kg}$ ) per bleeding episode from the DOSE registry.

1. Simultaneously varying prophylaxis efficacy and ABR. aPCC prophylaxis at the base case cost of $\$ 1.64$ per $U$ remained cost saving at an on-demand ABR of at least 22.2 and with a corresponding prophylaxis efficacy of at least $70.8 \%$ (Figure 2). Alternatively, when prophylaxis efficacy was less than $70.8 \%$ and the ABR was lower than 22.2, aPCC prophylaxis was not cost saving. Additionally, aPCC prophylaxis was cost saving when ABR was greater than 23 at efficacy rates greater than 54\%. Prophylaxis with rFVIIa at the base case cost of $\$ 1.71$ per $U$ was not cost saving over the range of prophylaxis efficacy and ABR considered.

2. Simultaneously varying $A B R$ and bypassing agent unit cost. At the base case prophylaxis efficacy of $72.5 \%$, prophylaxis with aPCC remained cost saving at an on-demand ABR of at least 21.2 and with a corresponding aPCC unit cost not exceeding \$1.56 (Appendix E-1, available in online article). As the ABR increased, the threshold unit cost of aPCC also increased. Prophylaxis with rFVIIa at the respective base case efficacy of $45 \%$ was not cost saving over the range of ABR and unit cost considered.

3. Simultaneously varying prophylaxis efficacy and bypassing agent unit cost. At the base case on-demand ABR of 28.7 bleeding episodes, prophylaxis with aPCC remained cost saving at a prophylaxis efficacy of at least $54.4 \%$ and a with corresponding aPCC unit cost not exceeding \$2.04 (Appendix E-2, available in online article). As prophylaxis efficacy increased, the threshold cost of aPCC also increased. Prophylaxis with rFVIIa was not cost saving over the range of prophylaxis efficacy and unit cost considered.

Comparison with rFVIIa on-demand dose (786 mcg per $\mathrm{kg}$ ) per bleeding episode from the HTRS registry.

1. Simultaneously varying prophylaxis efficacy and ABR. aPCC prophylaxis remained cost saving at the base case cost of $\$ 1.64$ per $U$ at an on-demand ABR of at least 21.2 and with a corresponding prophylaxis efficacy of at least $54.3 \%$. Over the range considered, these values represent the lower limits of ABR and prophylaxis efficacy. rFVIIa prophylaxis was not cost saving over the range of prophylaxis efficacy and ABR considered.

2. Simultaneously varying $A B R$ and bypassing unit cost. At the base case aPCC prophylaxis efficacy of $72.5 \%$, aPCC prophylaxis remained cost saving at an on-demand ABR of at least 

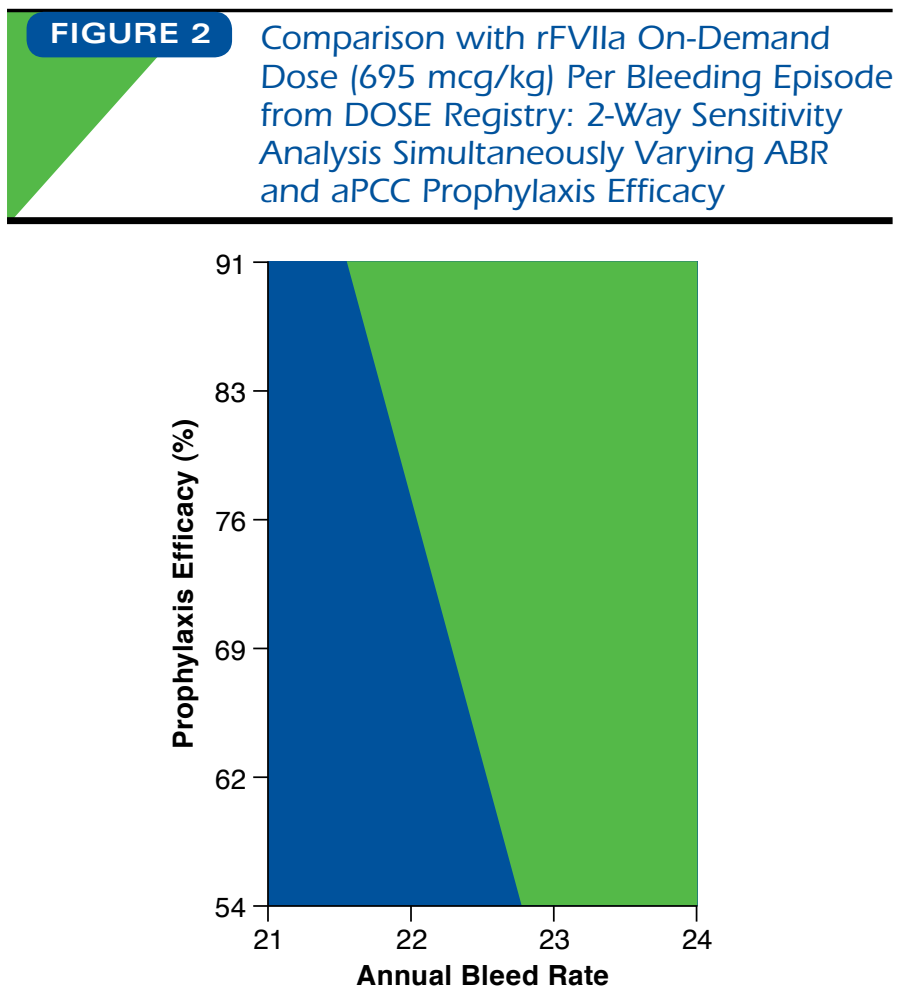

Note: Unit bypassing agent cost for aPCC was kept constant at the base case value of \$1.64 per Unit. Green shading indicates prophylaxis is cost saving. Blue shading indicates prophylaxis is not cost saving.

$A B R=$ annual bleed rate; $a P C C=$ activated prothrombin complex concentrate; DOSE = Dosing Observational Study in Hemophilia; $m c g / k g=$ microgram per kilogram; $r$ FVIIa = recombinant factor VIIa.

21.3 and with a corresponding aPCC unit cost not exceeding $\$ 1.77$ (Appendix F-1, available in online article). As the ABR increased, the threshold price of aPCC also increased. Prophylaxis with rFVIIa at the base case efficacy of $45 \%$ was not cost saving over the range of ABR and unit cost considered.

3. Simultaneously varying prophylaxis efficacy and bypassing unit cost. At the base case on-demand ABR of 28.7, the prophylaxis with aPCC remained cost saving at prophylaxis efficacy of at least $54.4 \%$ and with a corresponding aPCC unit cost not exceeding $\$ 2.32$ (Appendix F-2, available in online article). At the base case ABR, rFVIIa prophylaxis was not cost saving over the range of prophylaxis efficacy and unit cost considered.

Comparison with rFVIIa on-demand dose (450 mcg per $\mathrm{kg}$ ) per bleeding episode from the HTRS registry.

1. Simultaneously varying prophylaxis efficacy and ABR. aPCC prophylaxis at the base case cost of $\$ 1.64$ per $U$ remained cost saving at an on-demand ABR of at least 35.5 and with a corresponding prophylaxis efficacy of at least $54.9 \%$ (Figure 3 ). Prophylaxis with rFVIIa at the base case cost of $\$ 1.71$ per
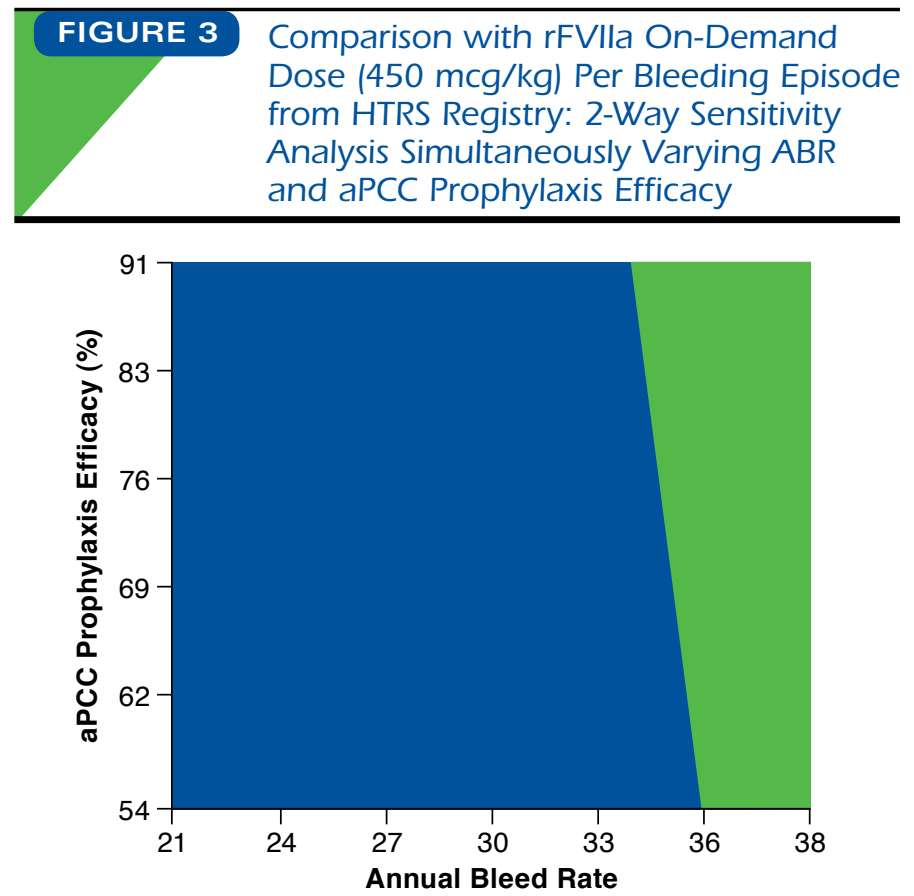

Note: Unit cost of aPCC was kept constant at base cost value of $\$ 1.64$ per Unit. Green shading indicates prophylaxis is cost saving. Blue shading indicates prophylaxis is not cost saving.

$A B R=$ annual bleed rate; $a P C C=$ activated prothrombin complex concentrate; HTRS = Haemophilia and Thrombosis Research Society; mcg/kg=microgram per kilogram; rFVIIa= recombinant factor VIIa.

U was not cost saving over the range of prophylaxis efficacy and on-demand ABR considered.

2. Simultaneously varying $A B R$ and bypassing unit cost. At the base case aPCC prophylaxis efficacy of $72.5 \%$, the prophylaxis with aPCC remained cost saving at on-demand ABR of at least 27 and with a corresponding aPCC unit cost not exceeding \$1.28 (Appendix G-1, available in online article). As ABR increased, the threshold cost of aPCC also increased. Prophylaxis with rFVIIa at base case efficacy of $45 \%$ was not cost saving over the range of on-demand ABR and unit cost considered.

3. Simultaneously varying prophylaxis efficacy and bypassing unit cost. At the base case on-demand ABR of 28.7, prophylaxis with aPCC remained cost saving at a prophylaxis efficacy of at least $54.4 \%$ and with a corresponding aPCC unit cost not exceeding \$1.32 (Appendix G-2, available in online article). As the prophylaxis efficacy increased, the threshold cost of aPCC also increased. At the base case ABR, rFVIIa prophylaxis was not cost saving over the range of prophylaxis efficacy and unit cost considered.

The results were robust when an aPCC prophylaxis dosing regimen of $85 \mathrm{U}$ per kg thrice weekly with a $62 \%$ efficacy $^{8}$ and 
a rFVIIa prophylaxis dosing regimen of 270 mcg per $\mathrm{kg}$ per day with a $59 \%$ efficacy ${ }^{9}$ were substituted in the model for the current base case parameters (Appendices A-C and $\mathrm{H}$, available in online article). The results also remained robust when similar 2-way sensitivity analyses presented for the base case scenario were conducted with these dosing regimens and corresponding efficacies. The results of the base case model also remained robust when WAC prices were substituted for ASP prices (Appendices I and J, available in online article).

\section{Discussion}

Prospective studies for bypassing agent prophylaxis have demonstrated substantive clinical benefits, including substantial and significant reduction in target joint bleeding events and reduced development of new target joint bleeds., ${ }^{5,8}$, Also, prophylaxis patients tend to experience lower hospitalization rates because of bleeding, ${ }^{10,25}$ improved joint health status, ${ }^{5,8}$ and improved productivity and better quality of life. ${ }^{10-12}$ In addition to the clinical benefits of prophylaxis, the results from the current analysis indicate that aPCC prophylaxis may even be cost saving for managing inhibitor patients who bleed frequently and infuse significant quantities of rFVIIa on-demand. The results suggest that switching this group of patients to a prophylaxis regimen may not necessarily increase their treatment cost as previously believed.

This study made use of median on-demand doses from 2 U.S. registries. For rFVIIa, the mean on-demand dosage (1,282.4 mcg per $\mathrm{kg}$ per bleeding episode) is higher than the median and hence the distribution is right skewed. ${ }^{17}$ For aPCC, because of the daily restriction of $200 \mathrm{U}$ per $\mathrm{kg}$, the mean and median on-demand doses obtained from the FEIBA NF PASS study tend to be close (unpublished data, Baxalta, October 10, 2014). Thus, this study may have in some cases underestimated the average cost saving due to a prophylaxis regimen. Since registry data on aPCC on-demand dosing has yet to be published, comparison of a prophylaxis regimen with aPCC on-demand was not part of the study objective. However, using the median on-demand dose for aPCC from the FEIBA NF PASS study (239.5 U per kg per bleeding episode [unpublished data, Baxalta, October 10, 2014]), the annual aPCC on-demand cost was $\$ 11,300.28$ per $\mathrm{kg}$. When this annual aPCC on-demand cost was compared with prophylaxis costs, the prophylaxis costs were higher $57 \%$ and $81 \%$ for aPCC and rFVIIa prophylaxis treatments, respectively). This remained robust even when prophylaxis efficacy and unit cost of bypass agents were varied over a range of $25 \%$ in a 1 -way sensitivity analysis. However, the aPCC and rFVIIa prophylaxis strategy only becomes cost saving when used in patients with ABRs higher than 67.39 and 154.16, respectively.

The results of our study are comparable with previously conducted studies in Spain and the United Kingdom. ${ }^{26,27}$ A cost analysis in Spain concluded that, compared with the cost of
rFVIIa on-demand treatment, aPCC prophylaxis could reduce the entire treatment cost of severe hemophilia A patients with inhibitors by $16 \% .{ }^{26}$ This conclusion translates into a savings in excess of 100,000 euros per inhibitor patient per year (in 2013 euros). Similarly, Hay et al. (2014) provided a cost comparison analysis based on rFVIIa on-demand doses reported in the UK National Haemophilia Database and showed that cost of aPCC prophylaxis was considerably less than previously thought. ${ }^{27}$ Hay et al. concluded that the overall benefits of prophylaxis may outweigh the incremental cost of treatment because of prophylaxis when managing inhibitor patients who bleed frequently and infuse significant quantities of rFVIIa on-demand. ${ }^{27}$

Several possible explanations exist for why multiple realworld studies have identified that the use of rFVIIa for treating bleeding episodes is significantly higher than what was reported in the clinical trials. First, patients' inability to distinguish when a bleeding episode ends has been speculated as a contributory factor, since pain and/or swelling of joints may persist after the end of an active bleed. ${ }^{18}$ Individuals often continue treatment until the pain and swelling subsides. ${ }^{17}$ Furthermore, because of the chronic nature of the disease, individual patients may have developed a better understanding of their bleeding episodes and the dose required to effectively resolve them, which in some cases may be based on the wrong notion of bleed resolution. Thus, an alternative to prophylaxis may be better patient education in order to reduce the total on-demand dose used. Other potential reasons lie in the short dosing frequency when using rFVIIa (2-3 hourly administrations), which creates more dosing opportunities in situations of suboptimal response, including unnecessary use of megadoses of rFVIIa. ${ }^{19}$

Results of the 2-way sensitivity analyses and threshold analyses indicate that aPCC prophylaxis was a cost-saving treatment option for many of the scenarios considered. rFVIIa prophylaxis, however, was a cost-saving proposition only at exceptionally high ABR or higher prophylaxis efficacy than was achieved in the rFVIIa clinical trial. When the threshold dose of on-demand rFVIIa (542.28 mcg per kg per bleeding episode) are compared with the median on-demand dose reported by the DOSE registry (695 mcg per kg per bleeding episode), we infer that aPCC prophylaxis is cost saving in greater than 50\% of the bleeding episodes. ${ }^{17}$ These bleeding episodes include all bleeding episodes in children (median dose per episode: 1,248.7 mcg per $\mathrm{kg}$ ) and those bleeds in adults (median dose per episode: $441.6 \mathrm{mcg}$ per $\mathrm{kg}$ ) who are treated on-demand above the threshold dose of $542.28 \mathrm{mcg}$ per $\mathrm{kg} .{ }^{28}$ On the other hand, rFVIIa prophylaxis would be cost saving in 50\% of children (median dose per episode: 1,248.7 mcg per $\mathrm{kg}$ ), but it is not cost saving in the majority of adults (median dose per episode: $441.6 \mathrm{mcg}$ per $\mathrm{kg}$ ). ${ }^{28}$ As compared with the overall median dose of $450 \mathrm{mcg}$ per $\mathrm{kg}$ in the HTRS registry, both 
aPCC and rFVIIa prophylaxes are cost saving in less than 50\% of the population. However, a greater proportion of bleeds would be cost saving with aPCC prophylaxis compared with rFVIIa prophylaxis. When the median dose of those bleeding episodes treated on-demand with megadoses of rFVIIa is considered, aPCC prophylaxis is cost saving for all patients, representing $8.5 \%$ of total bleeding episodes in the HTRS registry ${ }^{18,19}$ However, rFVIIa prophylaxis $(90 \mathrm{mcg}$ per $\mathrm{kg}$ ) would be cost saving in less than $8.5 \%$ of on-demand treated bleeding episodes. ${ }^{18,19}$

It is not expected that prophylaxis will, in the short term, be cost saving relative to on-demand therapy, given the regular administration of factor associated with prophylaxis. However, given that aPCC prophylaxis could be cost saving in patients who bleed frequently and have high on-demand use of bypassing factors, it may be substantially less costly than expected, while potentially providing considerable clinical and humanistic benefits. $5,8,10,11$

\section{Limitations}

This study does have certain limitations. The model inputs associated with prophylaxis (prophylaxis efficacy and number of infusions for resolution of break-through bleeds) were obtained from clinical trials so may not reflect real-world effectiveness and dosing. However, the base case parameters were varied in 2-way sensitivity analyses, and threshold values were reported for these parameters. The model only included costs associated with bypassing agents and did not consider other direct (e.g., hospitalization, surgery, and inpatient treatment costs) and indirect costs. However, we do not expect these additional costs to affect the study conclusion, since bypassing agents have been reported to account for the majority of the cost of care for hemophilia patients with inhibitors. This study may have even underestimated the cost savings due to prophylaxis, since we could not quantify the cost savings because of the reduction in incidence of development of new target joints and improvement in productivity and quality of life, as reported by other prophylaxis studies. ${ }^{9-12}$ The aPCC prophylaxis study reported bleeding in 7 new target joints in prophylaxis patients, as compared with 23 new target joints in patients treated on-demand. ${ }^{5}$ This finding represents a 69.5\% reduction in new target joint formation in the prophylaxis arms. The aPCC prophylaxis study was not powered for this outcome so was not included in the current analysis. If these costs had been included in our model, the cost saving benefit of prophylaxis would have been further strengthened.

\section{Conclusions}

Prospective studies have demonstrated that prophylaxis therapy with bypassing agents provides better clinical and humanistic outcomes when managing inhibitor patients. Given the high dose of rFVIIa reported to treat bleeds on-demand in the
United States, the study results presented here suggest that aPCC prophylaxis may be a cost-saving treatment option for inhibitor patients who bleed frequently and infuse significant quantities of rFVIIa on-demand.

\section{Authors}

DARSHAN A. MEHTA, MS, is a PhD Student, Pharmaceutical Economics and Policy, and JOEL W. HAY, PhD, is Professor, Pharmaceutical Economics and Policy, and Professor, Health Policy and Economics, University of Southern California, Los Angeles. ABIOLA O. OLADAPO, BPharm, PhD, is Senior Manager, Baxalta US, Cambridge, Massachusetts; JOSHUA D. EPSTEIN, PhD, was Director, Baxalta US, Westlake Village, California; and AARON R. NOVACK, PhD, is Senior Manager, Global Medical Affairs, Baxalta US, Deerfield, Illinois. ELLIS J. NEUFELD, MD, PhD, is Egan Family Foundation Chair in Transitional Medicine, Division of Hematology/Oncology, Boston Children's Hospital and Harvard Medical School, Boston, Massachusetts.

AUTHOR CORRESPONDENCE: Joel W. Hay, PhD, USC Schaeffer Center for Health Policy and Economics, Verna \& Peter Dauterive Hall (VPD), 635 Downey Way, Los Angeles, CA 90089-3333. Tel.: 818.338.5433; Fax: 213.740.3460 (ATTN: J Hay); E-mail: jhay@usc.edu.

\section{DISCLOSURES}

Mehta and Hay were financially supported by an unrestricted research agreement between Baxalta US and the University of Southern California The agreement specifically precluded the sponsor from altering, modifying, or censoring the findings. Neufeld received research funding through his institution from Baxalta US and from NovoNordisk and Octapharma and has served on advisory boards for Baxalta US and Novo Nordisk. Oladapo and Novack are employees of Baxalta US. Epstein was an employee of Baxalta at the time of this study.

All authors contributed to the development of the study concept, model design, and analyses plan. Mehta and Oladapo conducted the analysis and summarized the study results. All authors contributed to the writing, critical review, and editing of the paper and approved the manuscript for final submission.

\section{REFERENCES}

1. Srivastava A, Brewer AK, Mauser-Bunschoten EP, et al. Guidelines in management of hemophilia. Hemophilia. 2013;19(1):el-47.

2. Hemophilia Federation of America. Bleeding disorders: inhibitors. Available at: http://www.hemophiliafed.org/bleeding-disorders/inhibitors/. Accessed November 28, 2015.

3. Kempton CL, White GC 2nd. How we treat a hemophilia A patient with factor VIII inhibitor. Blood. 2009;113(1):11-17.

4. FEIBA, anti-inhibitor coagulant complex for intravenous use, lyophilized powder for solution. Baxter Healthcare. Revised November 2013. Available at: http://www.fda.gov/downloads/BiologicsBloodVaccines/BloodBloodProducts/ ApprovedProducts/LicensedProductsBLAs/FractionatedPlasmaProducts/ UCM221749.pdf. Accessed November 28, 2015. 
5. Antunes SV, Tangada S, Stasyshyn O, et al. Randomized comparison of prophylaxis and on-demand regimens with FEIBA NF in the treatment of haemophilia A and B with inhibitors. Haemophilia. 2014;20(1):65-72.

6. NovoSeven, coagulation factor VIIa (recombinant), for intravenous use only. Novo Nordisk. October 13, 2006. Available at: http://www.fda.gov/ downloads/BiologicsBloodVaccines/BloodBloodProducts/ApprovedProducts/ LicensedProductsBLAs/FractionatedPlasmaProducts/UCM056915.pdf. Accessed November 28, 2015

7. NovoSeven, $1.2 \mathrm{mg}$ (60 KIU), powder and solvent for solution for injection. Novo Nordisk. February 23, 2006. European Medicines Agency approval. Available at: http://www.ema.europa.eu/docs/en_GB/document_ library/EPAR_-_Product_Information/human/000074/WC500030873.pdf. Accessed November 28, 2015.

8. Lessinger C, Gringeri A, Antmen B, et al. Anti-inhibitor coagulant complex prophylaxis in hemophilia with inhibitors. N Engl J Med. 2011;365(18):1684-92

9. Konkle RA, Ebbesen LS, Erhardsten E, et al. Randomized prospective clinical trial of recombinant factor VIIa for secondary prophylaxis in hemophilia patients with inhibitors. J Throm Haemost. 2007;5(9):1904-13.

10. Stasyshyn O, Antunues S, Mamonov V, et al. Prophylaxis with antiinhibitor coagulant complex improves health-related quality of life in haemophilia patients with inhibitors: results from FEIBA NF Prophylaxis Study. Haemophilia. 2014;20(5):644-50.

11. Gringeri A, Leissinger C, Cortesi PA, et al. Health-related quality of life in patients with haemophilia and inhibitors on prophylaxis with anti-inhibitor complex concentrate: results from the Pro-FEIBA study. Haemophilia. 2013;19(5):736-43

12. Hoots WK, Ebbesen LS, Konkle BA, et al. Secondary prophylaxis with recombinant activated factor VII improves health-related quality of life of haemophilia patients with inhibitors. Haemophilia. 2008;14(3):466-75.

13. National Hemophilia Foundation. MASAC recommendation regarding prophylaxis with bypassing agents in patients with hemophilia and high titer inhibitors. Medical and Scientific Advisory Council (MASAC) document \#220. 2013. Available at: http://www.hemophilia.org/sites/default/files/ document/files/masac220.pdf. Accessed November 28, 2015.

14. Auerswald G, von Depka Prondzinski M, Ehlken B, et al. Treatment patterns and cost-of-illness of severe haemophilia in patients with inhibitors in Germany. Haemophilia. 2004;10(5):499-508.

15. Bohn RL, Aledort LM, Putnam KG, et al. The economic impact of factor VIII inhibitors in patients with haemophilia. Haemophilia. 2004;10(1):63-68.

16. Gringeri A, Lundin B, von Mackensen S, et al. A randomized clinical trial of prophylaxis in children with hemophilia A (the ESPRIT Study). J Throm Haemost. 2011;9(4):700-10.
17. Young G, Shapiro AD, Walse CE, Gruppo RA, Gut RZ, Cooper DL. Patient/caregiver-reported recombinant factor VIIa (rFVIIa) dosing: home treatment of acute bleeds in the Dosing Observational Study in Hemophilia (DOSE). Haemophilia. 2012;18(3):392-99.

18. Neufeld EJ, Saxena K, Kessler CM, Cooper DL; HTRS Investigators. Dosing, efficacy and safety of recombinant factor VIIa in pediatric versus adult patients: the experience of Hemostasis and Thrombosis Research Society (HTRS) registry (2004-2008). Pediatr Blood Cancer. 2013;60(7):1178-83.

19. Neufeld EJ, Kessler CM, Gill JC, Wilke CT, Cooper DL; HTRS Investigators. Exposure and safety of higher doses of recombinant factor VIIa $\geq 250 \mu \mathrm{g} \mathrm{kg} \mathrm{(-1)} \mathrm{in} \mathrm{individuals} \mathrm{with} \mathrm{congenital} \mathrm{haemophilia} \mathrm{compli-}$ cated by alloantibody inhibitors: the Haemophilia and Thrombosis Research Society Registry experience (2004-2008). Haemophilia. 2011;17(4):650-56.

20. Astermark J, Donfield SM, DiMichele DM, et al. A randomized comparison of bypassing agents in hemophilia complicated by an inhibitor: the FEIBA NovoSeven Comparative (FENOC) Study. Blood. 2007;109(2):546-51.

21. Johnson KA, Zhou ZY. Costs of care in hemophilia and possible implications of health care reform. Hematology Am Soc Hematol Educ Program. 2011;2011(1):413-18.

22. Gringeri A, Mantovani LG, Scalone L, Mannucci PM; COCIS Study Group. Cost of care and quality of life for patients with hemophilia complicated by inhibitors: the COCIS Study Group. Blood. 2003;102(7):2358-63.

23. Centers for Medicare $\&$ Medicaid Services. 2014 ASP drug pricing files December 8, 2014. Available at: https://www.cms.gov/Medicare/MedicareFee-for-Service-Part-B-Drugs/McrPartBDrugAvgSalesPrice/2014ASPFiles. html. Accessed November 30, 2015.

24. Academy of Managed Care Pharmacy. AMCP guide to pharmaceutical payment methods, 2009 update (version 2.0). J Manag Care Pharm. 2009;15(6 Suppl A):S3-57. Available at: http://www.amcp.org/data/ jmcp/1002.pdf.

25. Ewing N, Escuriola-Ettingshausen C, Kreuz W. Prophylaxis with FEIBA in paediatric patients with haemophilia A and inhibitors. Haemophilia. 2015(3);21:358-64.

26. Villarrubia R, Oyagüez I, Álvarez-Román MT, Mingot-Castellano ME, Parra R, Casado MA. Cost analysis of prophylaxis with activated prothrombin complex concentrate vs. on-demand therapy with activated factor VII in severe haemophilia A patients with inhibitors, in Spain. Haemophilia. 2015;21(3):320-29.

27. Hay JW, Oladapo AO, Epstein JD, Holmes S. Estimating the potential cost of bypassing agent prophylaxis relative to the cost of rFVIIa ondemand using actual rFVIIa doses from the UK NHD registry. Haemophilia. 2014;20(Suppl 2):79 [Abstract \#PO106].

28. Gruppo RA, Kessler CM, Neufeld EJ, Coopers DL. Assessment of individual dose utilization vs. physician prescribing recommendations for recombinant activated factor VII (rFVIIa) in paediatric and adult patients with congenital haemophilia and alloantibody inhibitors (CHwI): the Dosing Observational Study in Hemophilia (DOSE). Haemophilia. 2013;19(4):524-32. 
APPENDIX A Base Case Results: Comparison with rFVIla On-Demand Dose $(695 \mathrm{mcg} / \mathrm{kg})$ Per Bleeding Episode from DOSE Registry

\begin{tabular}{|c|c|c|c|}
\hline & $\begin{array}{l}\text { aPCC Prophylaxis } \\
\text { (85 U/kg/QOD) }\end{array}$ & $\begin{array}{l}\text { rFVIIa Prophylaxis } \\
\text { (90 mcg/kg/day) }\end{array}$ & $\begin{array}{l}\text { rFVIIa Prophylaxis } \\
\text { (270 mcg/kg/day) }\end{array}$ \\
\hline Annual on-demand rFVIIa cost, per kg of body weight (\$) & 34,009 & 34,009 & 34,009 \\
\hline Annual prophylaxis cost, per kg of body weight (\$) & 26,536 & 60,700 & 171,178 \\
\hline Number of bleed events avoided & 20.8 & 12.92 & 16.93 \\
\hline Cost saving due to prophylaxis, per kg of body weight $(\$)$ & $7,473.2$ & $-26,691$ & $-137,169$ \\
\hline Cost-effectiveness (cost per bleed events avoided) (\$) & 360 & $-2,066.7$ & $-8,100.7$ \\
\hline Cost reduction due to prophylaxis (\%) & 21.9 & -78 & -403 \\
\hline
\end{tabular}

Note: Positive value indicates prophylaxis is cost saving; negative value indicates prophylaxis is not cost saving.

aPCC = activated prothrombin complex concentrate; DOSE = Dosing Observational Study in Hemophilia; $\mathrm{kg}=$ kilogram; mcg $/ \mathrm{kg} /$ day = microgram per kilogram per day; QOD = every other day; $r$ FVIIa = recombinant factor VIIa; U/kg = Unit per kilogram.

\section{APPENDIX B Base Case Results: Comparison with rFVIla On-Demand Dose (786 mcg/kg) Per Bleeding} Episode from HTRS Registry

\begin{tabular}{|c|c|c|c|}
\hline & $\begin{array}{l}\text { aPCC Prophylaxis } \\
\text { (85 U/kg/QOD) }\end{array}$ & $\begin{array}{l}\text { rFVIIa Prophylaxis } \\
\text { (90 mcg/kg/day) }\end{array}$ & $\begin{array}{l}\text { rFVIIa Prophylaxis } \\
\text { (270 mcg/kg/day) }\end{array}$ \\
\hline Annual on-demand rFVIIa cost, per kg of body weight (\$) & 38,461 & 38,461 & 38,461 \\
\hline Annual prophylaxis cost, per kg of body weight (\$) & 26,536 & 60,700 & 171,178 \\
\hline Number of bleed events avoided & 20.8 & 12.92 & 16.93 \\
\hline Cost saving due to prophylaxis, per kg of body weight $(\$)$ & 11,926 & $-22,238$ & $-132,716$ \\
\hline Cost-effectiveness (cost per bleed events avoided) (\$) & 573.37 & $-1,721.9$ & $-7,837.7$ \\
\hline Cost reduction due to prophylaxis (\%) & 31 & -57.8 & -345 \\
\hline
\end{tabular}

\section{APPENDIX C) Base Case Results: Comparison with rFVIla On-Demand Dose (450 mcg/kg) Per Bleeding Episode from HTRS Registry}

\begin{tabular}{|c|c|c|c|}
\hline & $\begin{array}{l}\text { aPCC Prophylaxis } \\
\text { (85 U/kg/QOD) }\end{array}$ & $\begin{array}{l}\text { rFVIIa Prophylaxis } \\
\text { (90 mcg/kg/day) }\end{array}$ & $\begin{array}{l}\text { rFVIIa Prophylaxis } \\
\text { (270 mcg/kg/day) }\end{array}$ \\
\hline Annual on-demand rFVIIa cost, per kg of body weight (\$) & 22,020 & 22,020 & 22,020 \\
\hline Annual prophylaxis cost, per kg of body weight (\$) & 26,536 & 60,700 & 171,178 \\
\hline Number of bleed events avoided & 20.8 & 12.92 & 16.93 \\
\hline Cost saving due to prophylaxis, per kg of body weight (\$) & $-4,515$ & $-38,680$ & $-149,158$ \\
\hline Cost-effectiveness (cost per bleed events avoided) (\$) & -217 & $-2,995$ & $-8,808$ \\
\hline Cost reduction due to prophylaxis (\%) & -20.5 & -175 & -677 \\
\hline
\end{tabular}

Note: Positive value indicates prophylaxis is cost saving; negative value indicates prophylaxis is not cost saving.

aPCC = activated prothrombin complex concentrate; HTRS = Hemostasis and Thrombosis Research Society; $\mathrm{kg}=$ kilogram; $\mathrm{mcg} / \mathrm{kg} / \mathrm{day}=\mathrm{microgram}$ per kilogram per day; $Q O D=$ every other day; $r$ FVIIa = recombinant factor VIIa; $\mathrm{U} / \mathrm{kg}=$ Unit per kilogram. 


\begin{tabular}{|c|c|c|c|}
\hline & $\begin{array}{c}\text { On-Demand Dose as Per } \\
\text { DOSE Registry (\$) }\end{array}$ & 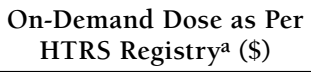 & $\begin{array}{l}\text { On-Demand Dose as Per } \\
\text { HTRS Registry }^{\text {b }}(\$)\end{array}$ \\
\hline Annual rFVIIa on-demand cost per patient & $1,700,450$ & $1,101,000$ & $1,923,050$ \\
\hline Annual rFVIIa on-demand cost for plan & $85,022,500$ & $55,050,000$ & $96,152,500$ \\
\hline Annual aPCC prophylaxis cost per patient & $1,326,750$ & $1,326,750$ & $1,326,750$ \\
\hline Annual aPCC prophylaxis cost for plan & $66,337,500$ & $66,337,500$ & $66,337,500$ \\
\hline Net impact from adopting aPCC prophylaxis regimen & $-18,685,000$ & $11,287,500$ & $-29,815,000$ \\
\hline PMPM for aPCC prophylaxis regimen & -0.16 & 0.09 & -0.25 \\
\hline Annual rFVIIa prophylaxis cost per patient & $3,035,000$ & $3,035,000$ & $3,035,000$ \\
\hline Annual rFVIIa prophylaxis cost for plan & $151,750,000$ & $151,750,000$ & $151,750,000$ \\
\hline Net impact from adopting rFVIIa prophylaxis regimen & $66,727,500$ & $96,700,000$ & $55,597,500$ \\
\hline PMPM for rFVIIa prophylaxis regimen & 0.56 & 0.81 & 0.46 \\
\hline
\end{tabular}

Note: Hypothetical plan with 10 million members considered. The plan was assumed to have 50 inhibitor patients based on prevalence of hemophilia of 1 in 10,000 patients and rate of inhibitor development of 5\%. Mean patient body weight of 50 kilograms was assumed.

a Median dose of $450 \mathrm{mcg} / \mathrm{kg} /$ bleeding episode.

bMedian dose of $786 \mathrm{mcg} / \mathrm{kg} / \mathrm{bleeding}$ episode.

aPCC = activated prothrombin complex concentrate; DOSE = Dosing Observational Study in Hemophilia; HTRS = Hemostasis and Thrombosis Research Society; mcg $/ \mathrm{kg} /$ bleeding episode = microgram per kilogram per bleeding episode; PMPM= per patient per month; $r$ FVIIa= recombinant factor VIIa .

APPENDIX E Comparison with rFVIla On-Demand Dose (695 mcg/kg) Per Bleeding Episode from DOSE Registry

\section{Two-Way Sensitivity Analysis: Simultaneously Varying Unit Cost of aPCC and ABR}



Note: aPCC prophylaxis efficacy was kept constant at the base case value of $72.5 \%$. Green shading indicates prophylaxis is cost saving.

$A B R=$ annual bleed rate; $a P C C=$ activated prothrombin complex concentrate DOSE = Dosing Observational Study in Hemophilia; $m c g / k g=$ microgram per kilogram; rFVIIa= recombinant factor VIIa.

\section{Two-Way Sensitivity Analysis: Simultaneously Varying} Prophylaxis Efficacy and Per Unit Cost of aPCC

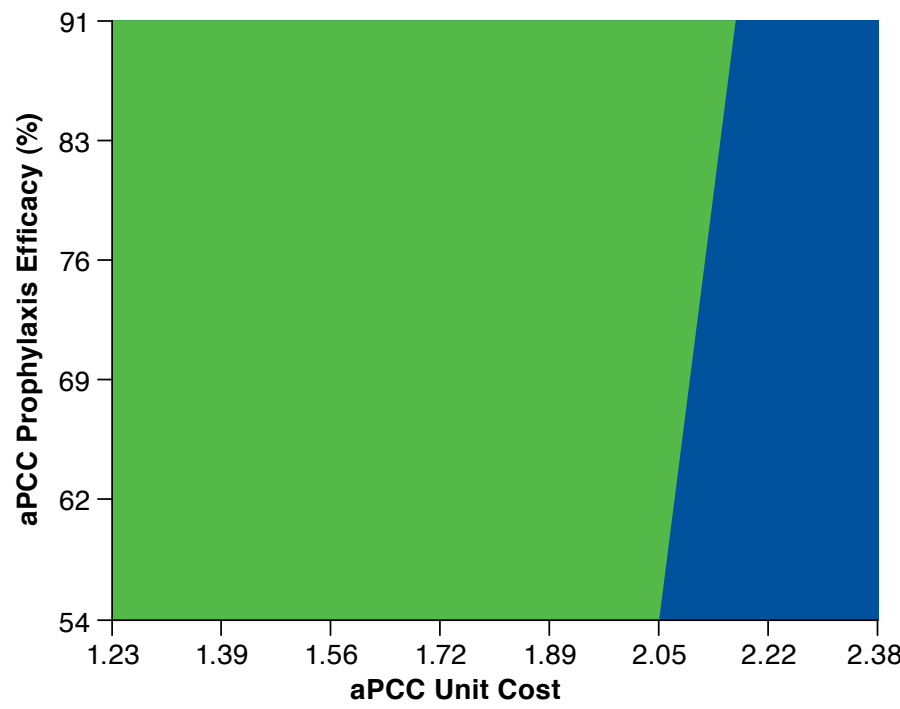

Note: Annual bleed rate was kept constant at the base case value of 28.7; Green shading indicates prophylaxis is cost saving.

aPCC= activated prothrombin complex concentrate. 
APPENDIX F Comparison with rFVIla On-Demand Dose (786 mcg/kg) Per Bleeding Episode from HTRS Registry

1. Two-Way Sensitivity Analysis: Simultaneously Varying ABR in Patients and Per Unit Cost of aPCC

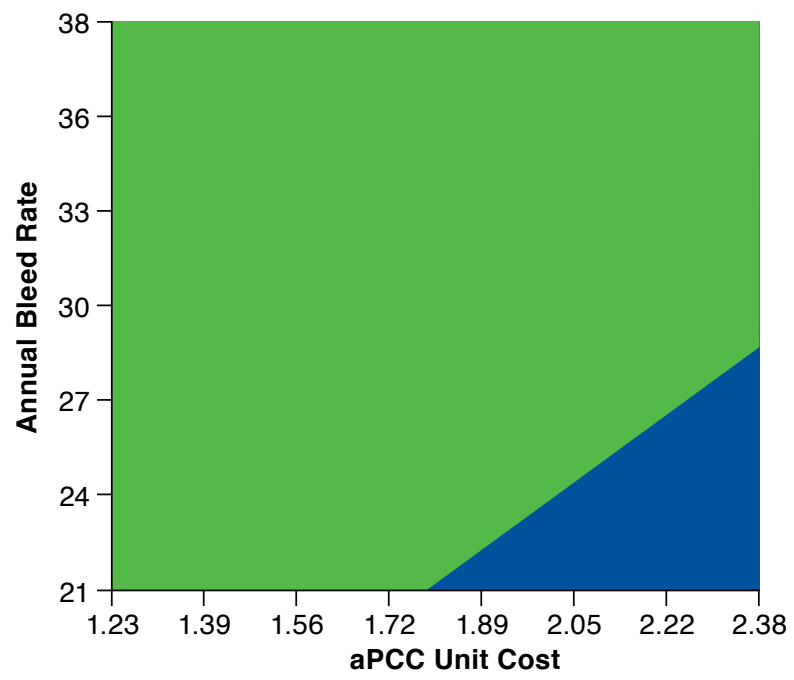

Note: aPCC prophylaxis efficacy was kept constant at the base case value of $72.5 \%$. Green shading indicates prophylaxis is cost saving.

$A B R=$ annual bleed rate; $a P C C=$ activated prothrombin complex concentrate; HTRS = Hemostasis and Thrombosis Research Society; $m c g / k g=$ microgram per kilogram; rFVIIa= recombinant factor VIIa.
2. Two-Way Sensitivity Analysis: Simultaneously Varying Cost of aPCC and Prophylaxis Efficacy

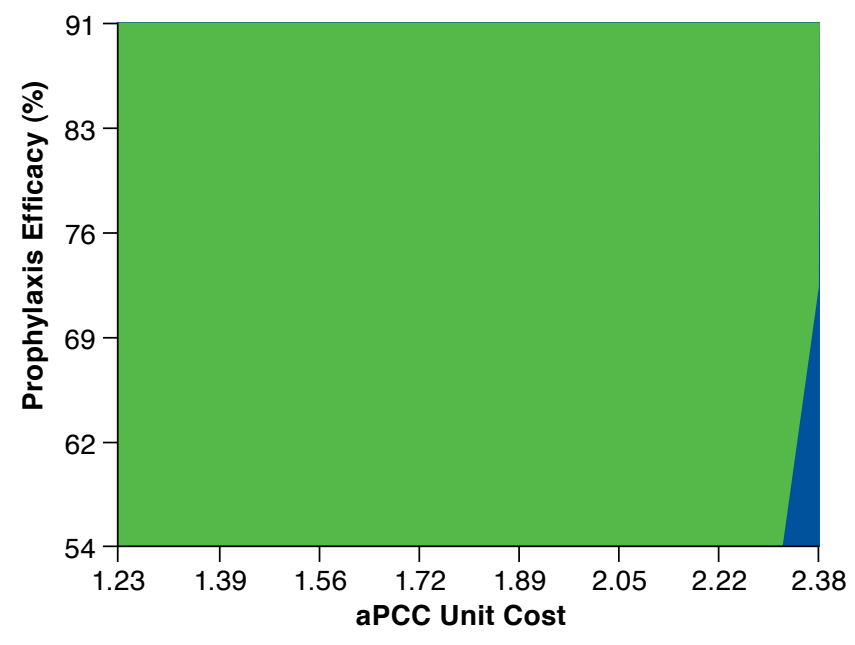

Note: Annual bleed rate was kept constant at the base case value of 28.7. Green shading indicates prophylaxis is cost saving. aPCC $=$ activated prothrombin complex concentrate.

APPENDIX G Comparison with rFVIla On-Demand Dose (450 mcg/kg) Per Bleeding Episode from HTRS Registry

1. Two-Way Sensitivity Analysis: Simultaneously Varying ABR and Unit Cost of aPCC

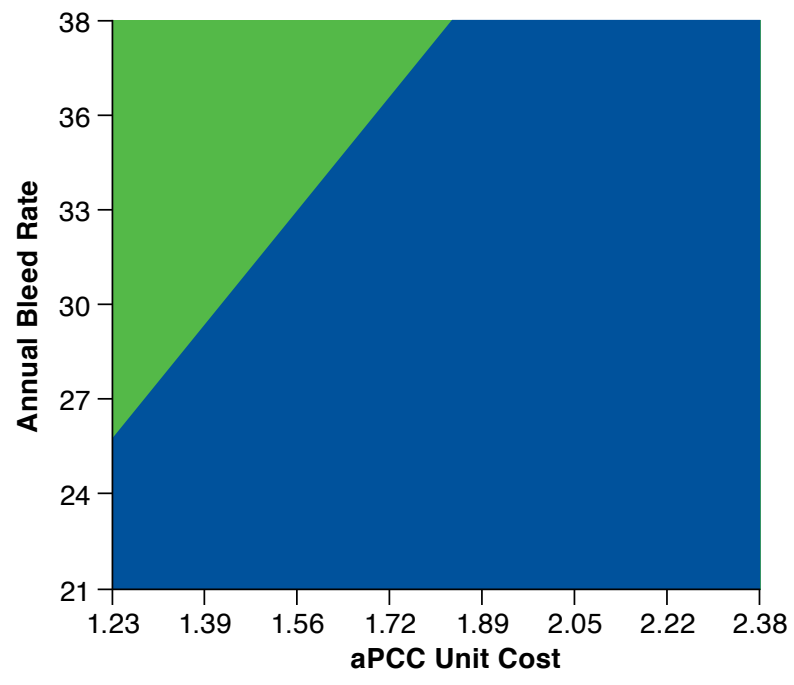

Note: Prophylaxis efficacy was kept constant at the base case value of $72.5 \%$ Green shading indicates prophylaxis is cost saving.

$A B R=$ annual bleed rate; $a P C C=$ activated prothrombin complex concentrate; HTRS = Hemostasis and Thrombosis Research Society; $m c g / k g=$ microgram per kilogram; $r$ FVIIa = recombinant factor VIIa.
2. Two-Way Sensitivity Analysis: Simultaneously Varying Prophylaxis Efficacy and Unit Cost of aPCC

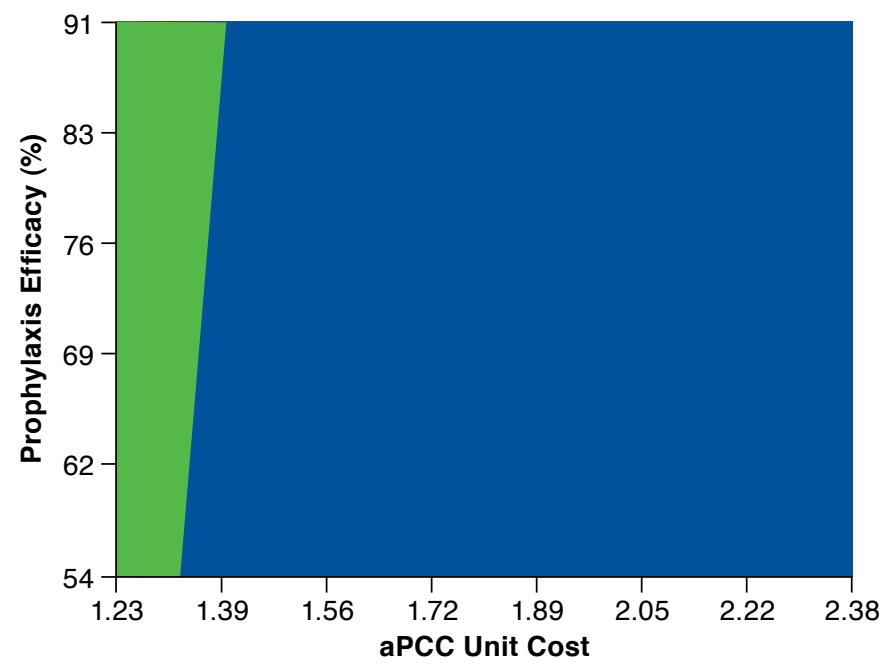

Note: Annual bleed rate was kept constant at the base case value of 28.7. Green shading indicates prophylaxis is cost saving.

aPCC = activated prothrombin complex concentrate. 
APPENDIX H Result of Univariate Sensitivity Analysis, Substituting for Pro-FEIBA Study Inputs

\begin{tabular}{l|c|c|c}
\hline & $\begin{array}{c}\text { DOSE Registry } \\
\text { (695 mcg/kg Per } \\
\text { Bleeding Episode) }\end{array}$ & $\begin{array}{c}\text { HTRS Registry } \\
(786 \text { mcg/kg Per } \\
\text { Bleeding Episode) }\end{array}$ & $\begin{array}{c}\text { HTRS Registry } \\
\text { (450 mcg/kg Per } \\
\text { Bleeding Episode) }\end{array}$ \\
\hline Annual on-demand rFVIla cost, per kg of body weight (\$) & 34,009 & \multicolumn{2}{|c|}{38,461} \\
\hline Annual aPCC prophylaxis cost, per kg of body weight (\$) & \multicolumn{2}{|c|}{23,323} & 22,020 \\
\hline Cost reduction due to prophylaxis (\%) & 31.4 & 39.4 & -5.6 \\
\hline
\end{tabular}

Note: Positive value indicates prophylaxis is cost saving; negative value indicates prophylaxis is not cost saving. aPCC = activated prothrombin complex concentrate; DOSE = Dosing Observational Study in Hemophilia; HTRS = Hemostasis and Thrombosis Research Society; $\mathrm{kg}=$ kilogram; $\mathrm{mcg} / \mathrm{kg}=$ microgram per kilogram; $r$ FVIIa= recombinant factor VIIa

\section{APPENDIX I Comparison of Unit Costs of aPCC and rFVIla Using 3 Base Case Scenarios}

\section{Scenario 1. DOSE Registry}



Note: Annual bleed rate $=28.7$; prophylaxis efficacy $=72.5 \%$. Green shading indicates prophylaxis is cost saving. aPCC $=$ activated prothrombin complex concentrate; DOSE = Dosing Observational Study in Hemophilia; mcg = microgram; $r$ FVIIa = recombinant factor VIIa; $U=$ unit $;$ WAC $=$ wholesale acquisition cost.

\section{Scenario 2. HTRS (786 mcg/kg) Registry}



Note: Annual bleed rate $=28.7$; prophylaxis efficacy $=45 \%$ Green shading indicates prophylaxis is cost saving. aPCC = activated prothrombin complex concentrate; HTRS = Hemostasis and Thrombosis Research Society; $m c g / k g=$ microgram per kilogram; $r$ FVIIa = recombinant factor VIIa; $U=$ unit; WAC = wholesale acquisition cost.

\section{Scenario 3. HTRS (450 mcg/kg) Registry}

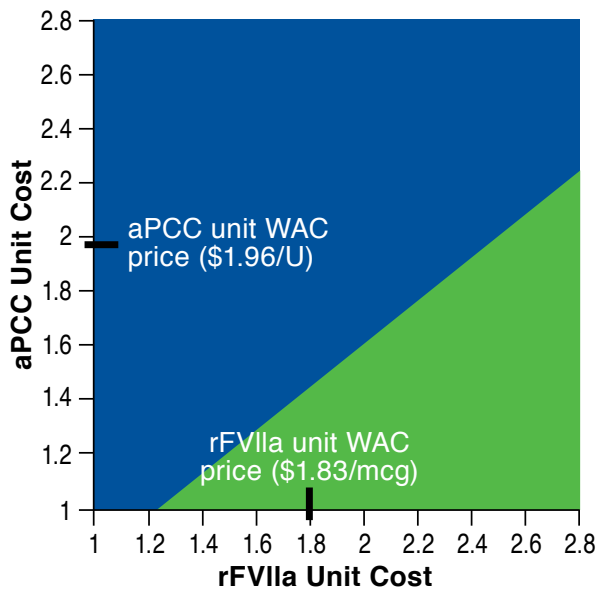

Note: Annual bleed rate $=28.7$; prophylaxis efficacy $=45 \%$. Green shading indicates prophylaxis is cost saving. aPCC = activated prothrombin complex concentrate; HTRS = Hemostasis and Thrombosis Research Society; $\mathrm{mcg} / \mathrm{kg}=$ microgram per kilogram; $r$ FVIIa = recombinant factor VIIa; $U=$ unit; WAC $=$ wholesale acquisition cost. 


\section{APPENDIX J Annual Treatment Cost Per Kilogram of rFVIla On-Demand Versus aPCC and rFVIla Prophylaxis ${ }^{\mathrm{a}}$}

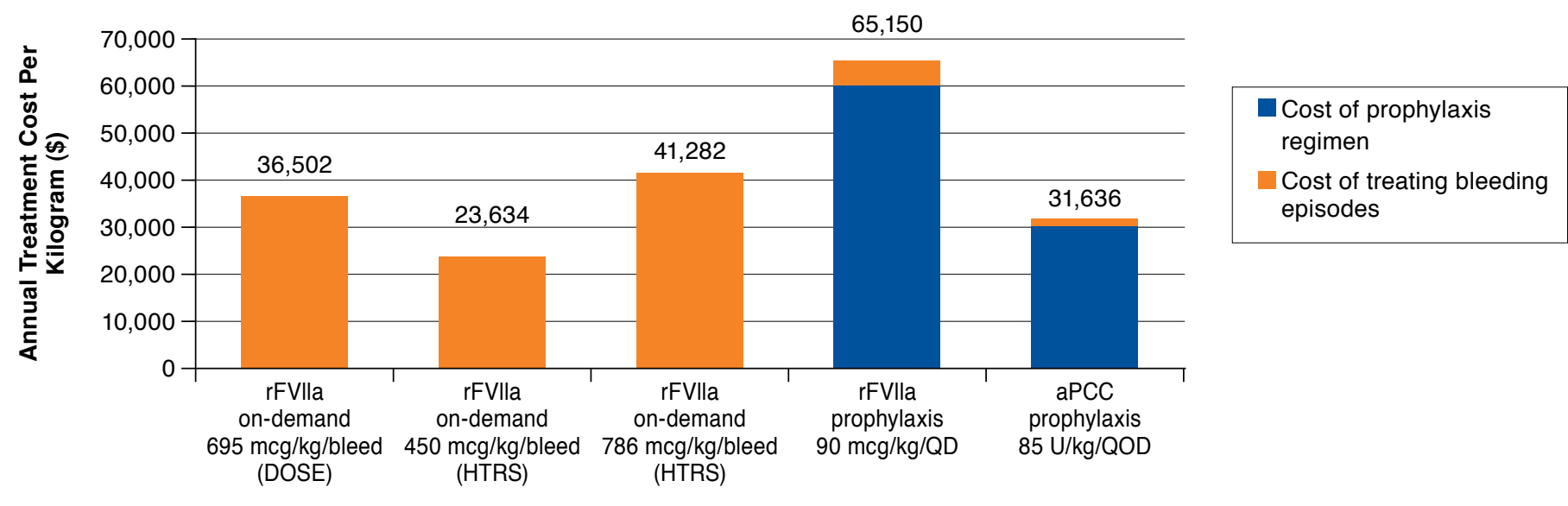

aWAC unit prices of bypassing agents substituted for ASP prices.

aPCC = activated prothrombin complex concentrate; $A S P=$ average sale price; DOSE = Dosing Observational Study in Hemophilia; HTRS=Hemostasis and Thrombosis Research Society; $\mathrm{mcg} / \mathrm{kg}=$ microgram per kilogram; $Q D=$ every day; $Q O D=$ every other day; $r F V I I a=$ recombinant factor VIIa; U=unit; WAC= wholesale acquisition cost. 